\section{A Clinicoepidemiological Study of Psoriasis and its Association with Metabolic Syndrome}

\section{Rashmi Singh ${ }^{1 *}$ and Prasoon Kumar Roy ${ }^{2}$ \\ ${ }^{1}$ Department of Dermatology, Heritage Institute of Medical Sciences, Uttar} Pradesh, India

${ }^{2}$ Department of Dermatology, Nalanda Medical College, Bihar, India

\begin{abstract}
Background: Psoriasis is an immune-mediated inflammatory disease, characterized by epidermal hyper-proliferation, abnormal keratinocyte differentiation, angiogenesis, vasodilatation and excess Th1/Th17 mediated inflammation,\& affects $2-3 \%$ of the population worldwide. Recently, many literatures have shown its association with metabolic syndrome
\end{abstract}

Aim: To study the epidemiological aspect and its association with metabolic syndrome

Study Design: The epidemiological part was done as a cross-sectional study and association was seen by performing a case control study

Materials and Methods: After obtaining approval from institutional ethical committee, all diagnosed cases of psoriasis in outpatient department of dermatology of our college were included for epidemiological study. All cases were subjected to detailed history. Of these 150 new cases who had not taken any treatment in the past 6 months were selected. After obtaining written informed consent 150 cases were confirmed by biopsy and further investigated to see the association with metabolic syndrome. Also, 150 age and sex matched controls from general population (e.g. attendants, hospital staffs and colleagues ) were similarly investigated. The severity of the disease among cases was assessed using PASI scoring.

Statistical Method: Results for continuous parameters are presented as mean $\pm S D$ and for categorical parameters as percentage. Significance is assessed at $5 \%$ level of significance. ANOVA has been

*Corresponding author: Rashmi Singh, Department of Dermatology, Heritage Institute of Medical Sciences, Uttar Pradesh, India, Tel: +91 9386233538; E-mail: rrakesh_75@yahoo.com

Citation: Singh R, Roy PK (2020) A Clinicoepidemiological Study of Psoriasis and its Association with Metabolic Syndrome. J Clin Dermatol Ther 6: 049.

Received: May 05, 2020; Accepted: May 15, 2020; Published: May 22, 2020

Copyright: ( $) 2020$ Singh R, et al. This is an open-access article distributed under the terms of the Creative Commons Attribution License, which permits unrestricted use, distribution, and reproduction in any medium, provided the original author and source are credited. used for comparing three or more groups, Chi square and /T test for comparing two or more groups

Result: Out of 150 psoriasis patients, $18 \%$ were diabetic as compared to $14 \%$ controls, $14 \%$ cases had hypertension in comparison to $15.33 \%$ of controls, both data being insignificant and hyperlipidemia though seen in a good number of patients of psoriasis was not statically significant.

Conclusion: Though, there are plenty of reports from west approving association of psoriasis and metabolic syndrome it can be explained on the basis of increased prevalence of obesity, abnormal BMI and hypertension in westerners as compared to Indian patients and our study refuted any such association

Keywords: Association; Clinicoepidemiological, Metabolic syndrome; Psoriasis

\section{Introduction}

Psoriasis is an immune-mediated inflammatory disease, characterized by epidermal hyper-proliferation, abnormal keratinocyte differentiation, angiogenesis, vasodilatation and excess Th1/Th17 inflammation, affects $2-3 \%$ of the population worldwide [1].

The term "Psoriasis" embraces a spectrum of diseases ranging from localized plaques to more severe generalized involvement, with or without psoriatic arthritis and other autoimmune diseases.

Psoriasis predominantly affects the skin with erythematous plaques and adherent silvery white scales involving mainly the extensor surfaces of the body like scalp, back, elbows, knees etc. Chronic plaque psoriasis is the most common morphological form with localized and generalized pustular forms less commonly seen.

\section{Etiopathogenesis of Psoriasis}

The etiology of psoriasis is unknown but genetic, metabolic and immunologic mechanisms have been proposed.Approximately $30 \%$ of patients with psoriasis have been reported to have an affected first degree relative, risk being 2-3 times greater in monozygotic twins than dizygotic twins [2]. The best-established genetic linkage is with PSORSI gene,which reportedly accounts for majority of individuals with genetic susceptibility to psoriasis.

Genetic susceptibility and overlapping inflammatory pathways may be potential biological links underlying this association [3].

Due to the role of auto-immune mechanisms in the pathogenesis of psoriasis, it is regarded as a systemic disease [4].

\section{Epidemiology}

A comprehensive data from various medical colleges of India suggests that the incidence of psoriasis among total skin patients ranged between 0.44 and $2.2 \%$, with overall incidence of $1.02 \%$ [5]. The ratio of male to female $(2.46: 1)$ was very high which could not be clearly 
accounted for. Highest incidence was noted in the age group of 20-39 years [6].

Types of psoriasis: Two clinical presentations of psoriasis, type I and II, are distinguished by a bimodal age at onset. Type 1 begins on or before age 40 years; Type II begins after the age of 40 years. Type I disease accounts for more than $75 \%$ of cases [7].

\section{Co-morbidities in psoriasis}

Recently, a number of co-morbidities have been described in psoriasis patients, including cardiovascular co-morbidities, metabolic syndrome and malignancies $[8,9]$. Hypertension, heart failure and diabetes mellitus have been found to be more common among psoriasis patients [9].

Metabolic Syndrome(MS), defined as a cluster of risk factors including central obesity, atherogenic dyslipidemia, hypertension and glucose intolerance, is a strong predictor of cardiovascular disease, that confers a cardiovascular risk higher than the individual components.

The chronically high levels of free fatty acids associated with both metabolic syndrome and psoriasis may lead to adipocyte dysfunction and inhibit insulin secretion, and also induce apoptosis of pancreatic b-islet cells through an endoplasmic stress response leading to the development of type 2 diabetes [10].

Psoriasis is associated with MS, independent of its severity [11].

It has been seen that the chronic and systemic Th-1- and Th-17-mediated inflammation of psoriasis characterized by increased levels of pro-inflammatory cytokines, e.g. tumor necrosis factor- $\alpha$ and interleukin-6,that not only promotes epidermal hyperplasia in psoriasis, but also antagonizes insulin signaling, alters adipokine expression, and mediates insulin resistance and obesity [3,12]. Furthermore,Obesity is associated with severe psoriasis and is reported about twice as frequently among psoriasis patients as in the general population. The association between psoriasis and metabolic syndrome is also true for mild severity psoriasis and is independent from the tendency of psoriatic patients to be obese [11].

The combined dysfunction of leptin, adiponectin, resist in, and visfatin described in psoriasis may account for the development of metabolic syndrome and other conditions associated with atherosclerosis seen in patients with psoriasis $[13,14]$.

Recent studies have estimated prevalence of MS to be $15-24 \%$ in the general population and $30-50 \%$ among psoriasis patients.

This increased frequency imposes a substantial burden on the overall health of psoriasis patients, which needs to be appropriately addressed during treatment of such patients.

Though, many foreign studies on association of MS with psoriasis has recently been done, but such Indian studies are still lacking.

Further, dermatologists taking care of psoriasis should know about such associations of diabetes and hypertension with psoriasis so that they can advise them regarding risk factors and about how to reduce them.

The present study has been undertaken to study association of psoriasis with various components of metabolicsyndrome and PASI.

\section{Methodology}

\section{Source of data}

The study comprised of cases of psoriasis visiting outpatient department of dermatology of Patna medical college, Patna, Bihar.

\section{Methodology and type of data collected:}

After obtaining clearance and approval from institutional ethical committee, all diagnosed cases of psoriasis in outpatient department of dermatology of Patna Medical College were included for epidemiological study.

All cases were subjected to detailed history including demographic data, drug history, personal history and family history,past and present medical history and drug intake as per the proforma attached in the Annexure1. Demographic and drug intake data was collected. Cases were also classified based on their occupational status.

Out of 372 patients fulfilling above criteria, after obtaining written informed consent 150 cases were confirmed by biopsy and further investigated to see the association with metabolic syndrome. Also, 150 age and sex matched individuals from general population (eg., attendants, hospital staffs and colleagues) were similarly investigated.

The severity of the disease among cases was assessed using PASI scoring and patient divided into mild $(<3)$, moderate $(3-10)$ and severe $(>10)$. Waist circumference was measured by locating the uppermost part of hip bone and placing a measuring tape around abdomen ,tight enough but without compressing the skin, and keeping it horizontal. Blood pressure was recorded as an average of two measurements, taken 5 minutes apart after the subjects had been at rest for 10 minutes. A $5 \mathrm{ml}$ venous blood sample was collected from both cases and controls, after overnight fasting ( 8 hours fast) and sent for laboratory biochemical estimations.

\section{Determinations}

- Plasma glucose was tested by glucose oxidase method

- Serum total cholesterol was estimated by enzymatic method

- Serum triglyceride (S.TG) was determined by enzymatic method

- Serum HDL Cholesterol (S.HDL) was estimated by phosphotungsate method

Criteria for hyperglycemia, hypertension, hyperlipidemia, obesity

- Fasting glucose $\geq 100 \mathrm{mg} / \mathrm{dl}$.

- Blood pressure $\geq 130 / 85 \mathrm{~mm} \mathrm{Hg}$ (Recorded in right arm in supine position after 30 minutes of rest with sphygmomanometer or on treatment for hypertension)

- Triglycerides $\geq 150 \mathrm{mg} / \mathrm{dL}$ (or receiving drug therapy for hypertriglyceridemia)

- $\mathrm{HDL}<40 \mathrm{mg} / \mathrm{dLin}$ males and $<50$ in females

- Waist circumference $\geq 102 \mathrm{~cm}$ (40 in) in men or $\geq 88 \mathrm{~cm}$ (35 in) in women

Metabolic syndrome was diagnosed using modified NCEP(National Cholesterol Education program's Adult Treatment Panel III) criteria if $\geq 3$ of above parameters were present. 


\section{Scores}

Patients were graded according to PASI (PSORIASIS AREA SEVERITY INDEX).

\section{PASI}

PASI scoring was done using following formula:

$\mathrm{PASI}=0.1(\mathrm{Eh}+\mathrm{Ih}+\mathrm{Dh}) \mathrm{A}+0.2(\mathrm{Eu}+\mathrm{Iu}+\mathrm{Du}) \mathrm{A}+0.3(\mathrm{Et}+\mathrm{It}+\mathrm{Dt}) \mathrm{A}+0.4$ $(\mathrm{El}+\mathrm{Il}+\mathrm{Dl}) \mathrm{A}$.

$\mathrm{E}=$ Erythema, I=Induration, $\mathrm{D}=$ Desquamation, $\mathrm{h}=$ Head, $\mathrm{u}=$ Upper lim$\mathrm{b}, \mathrm{t}=$ Trunk, $\mathrm{l}=$ Lowerlimb

The scores can vary from $1-72$ in steps of 0.1 .

\section{In our study:}

PASI $:<3$ was graded as MILD

3- 10 was graded as MODERATE

$>10$ was graded as SEVERE

\section{Statistical analysis}

Results for continuous parameters are presented as mean \pm SD and for categorical parameters as percentage. Significance is assessed at $5 \%$ level of significance\&Chi square and /T test have been used for comparing two or more groups (Graphs 1-5). The stastical analysis software epiinfo 7 was used to analyse the data (Tables 1-6).

\begin{tabular}{|c|c|c|c|c|}
\hline Diabetes & \multicolumn{2}{|c|}{ Cases } & \multicolumn{2}{c|}{ Control } \\
\hline & No & $\%$ & No & $\%$ \\
\hline Yes & 27 & 18 & 21 & 14 \\
\hline No & 123 & 82 & 127 & 86 \\
\hline & 150 & 100 & 150 & 100 \\
\hline & \multicolumn{2}{|c|}{$75 \pm 67.88$} & \multicolumn{2}{c|}{$75 \pm 76.37$} \\
\hline
\end{tabular}

Table 1: Diabetes among cases and controls.

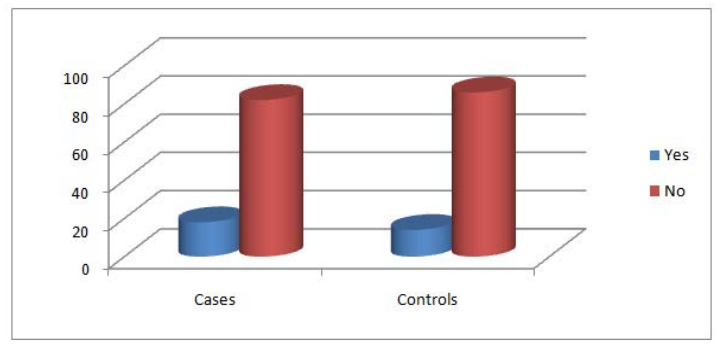

Graph 1: Diabetes in cases and controls.

\begin{tabular}{|c|c|c|c|c|}
\hline Diabetes & \multicolumn{2}{|c|}{ Cases } & \multicolumn{2}{c|}{ Control } \\
\hline & No & $\%$ & No & $\%$ \\
\hline Yes & 20 & 13.33 & 23 & 15.33 \\
\hline No & 130 & 86 & 127 & 84.67 \\
\hline Total & 150 & 100 & 150 & 100 \\
\hline Mean \pm SD & \multicolumn{2}{|c|}{$75 \pm 76.36$} & \multicolumn{2}{c|}{$75 \pm 73.53$} \\
\hline
\end{tabular}

Table 2: Hypertension among cases and controls.

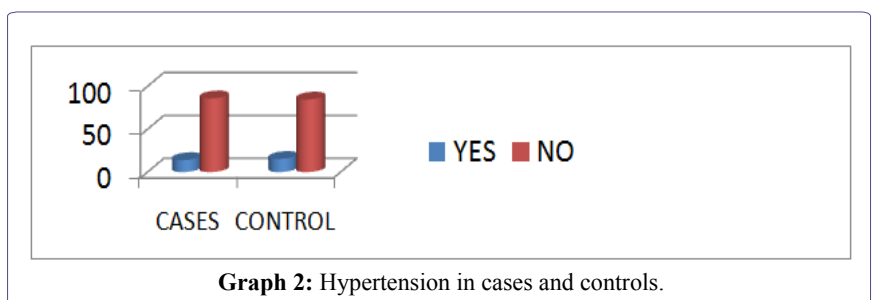

Graph 2: Hypertension in cases and controls.

\begin{tabular}{|c|c|c|c|c|c|}
\hline Diabetes & \multicolumn{2}{|c|}{ Cases } & \multicolumn{2}{c|}{ Control } & Pvalue \\
\hline & No & $\%$ & No & $\%$ & \\
\hline Yes & 26 & 17.33 & 20 & 13.33 & 0.423 \\
\hline No & 124 & 93.67 & 130 & 86.67 & \\
\hline Total & 150 & 100 & 150 & 100 & \\
\hline \multicolumn{5}{|c|}{ Table 3: Obesity among cases and controls. } \\
\hline
\end{tabular}

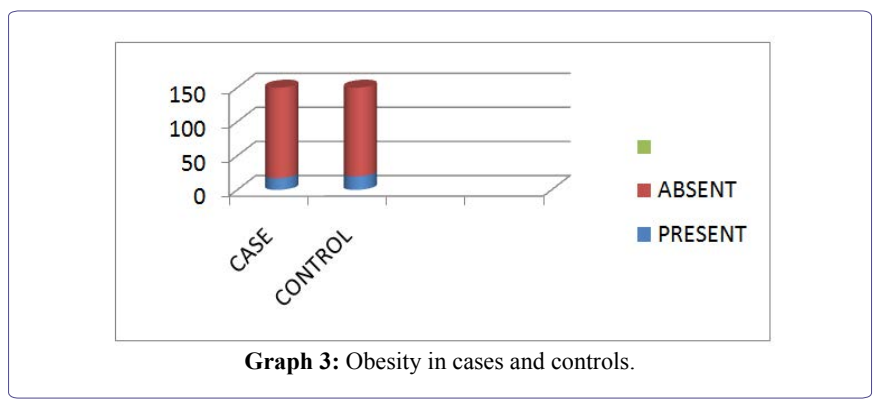

\begin{tabular}{|c|c|c|c|c|c|}
\hline & Cases NO. & $\mathbf{\%}$ & Control no. & $\mathbf{\%}$ & $\mathbf{9 5 \% ~ C I ~}$ \\
\hline $\mathrm{Sr}$ TG $<150$ & 83 & 55.33 & 86 & 57.33 & $0.68-1.71$ \\
\hline$>150$ & 67 & 44.67 & 64 & 42.67 & \\
\hline $\begin{array}{c}\mathrm{HDL}<40 \text { in } \\
\text { males, }<50 \text { in } \\
\text { femaless }\end{array}$ & 50 & 33.33 & 57 & 38 & $0.50-1.30$ \\
\hline $\begin{array}{c}>40 \text { in males } \\
>50 \text { in females }\end{array}$ & 100 & 66.67 & 93 & 62 & \\
\hline \multicolumn{6}{|c|}{ Table 4: Lipid profile among cases and controls. } \\
\hline
\end{tabular}

\begin{tabular}{|c|c|c|c|c|c|c|c|c|}
\hline \multirow{2}{*}{$\begin{array}{c}\text { Metabolic } \\
\text { Syndrome }\end{array}$} & \multicolumn{2}{|c|}{ Cases } & \multicolumn{2}{c|}{ Control } & \multicolumn{2}{|c|}{ Total } & \multirow{2}{*}{ Chi-square test } \\
\cline { 2 - 10 } & $\mathrm{N}$ & $\%$ & $\mathrm{~N}$ & $\%$ & & & \multirow{2}{*}{$\mathrm{x}^{2}$} & P value \\
\hline Present & 16 & 10.7 & 13 & 8.7 & 29 & 9.7 & 0.344 & 0.697 \\
\hline Absent & 134 & 89.3 & 137 & 91.3 & 271 & 90.3 & & \\
\hline Total & 150 & 100 & 100 & 100 & 300 & 100 & & \\
\hline \multicolumn{7}{|c|}{ Table 5: Metabolic syndrome among cases and controls. }
\end{tabular}

\section{Discussion}

Association of psoriasis with metabolic syndrome

Association with hyperglycemia

Few Indian studies have shown association of psoriasis with hyperglycemia as in the study done by Sundharam JA, et al. which had 
shown relationship between abnormal glucose tolerance and psoriasis [15].

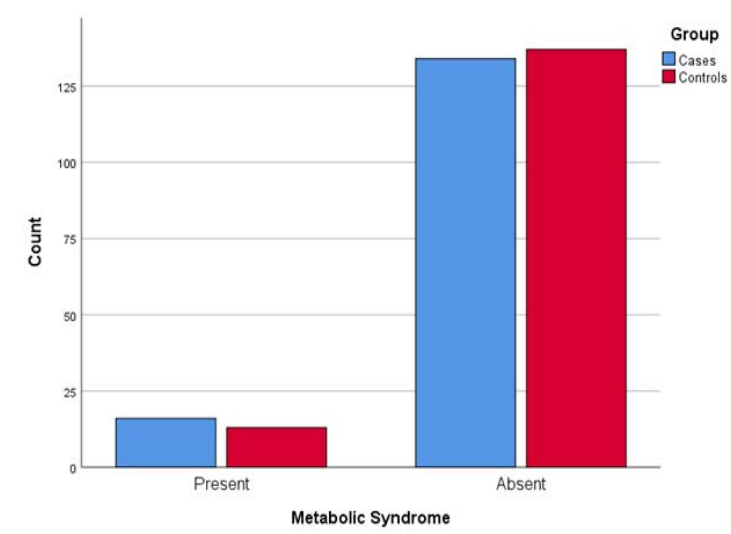

Graph 4: Metabolic syndrome in cases and controls.

\begin{tabular}{|c|c|c|c|c|}
\hline \multirow{2}{*}{} & \multicolumn{2}{|c|}{ Cases } & \multicolumn{2}{c|}{ Control } \\
\cline { 2 - 5 } & MS+ & MS- & $\mathrm{t}$ & P value \\
\hline PASI & 8.09 & 3.97 & -1.062 & 0.290 \\
\hline
\end{tabular}

Table 6: Mean PASI in individuals with or without MS.

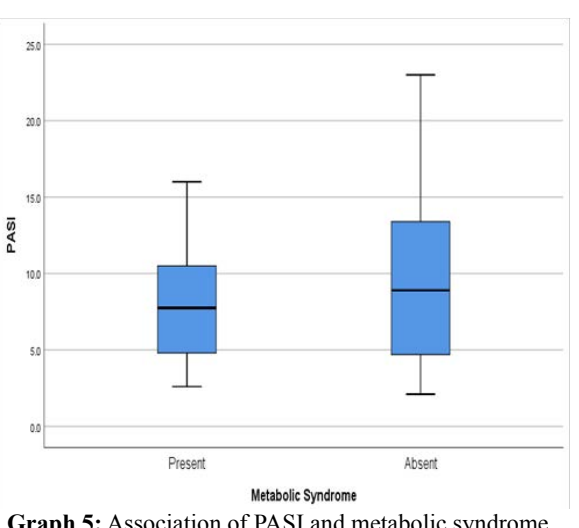

Graph 5: Association of PASI and metabolic syndrome.

Also, an Indian study by Alexander et al. revealed a prevalence of diabetes in $13.1 \%$ of psoriasis patients [16].

Yet another study done by, Madanagobalane S et al., found an association between hyperglycemia and psoriasis [17].

However, western studies show more consistent results with significant association of diabetes with psoriasis seen in most of them.

Neimann et al, Sommer et al, Shapiro et al and Cohen et al., all reported an increase in the prevalence of diabetes in patients with psoriasis [18-20].

Ali NM, Kuruvila M, Unnikrishnan B, et al. found an association with all components of metabolic syndrome except hyperglycemia [21].
Lonnberg et al. found a significant association between psoriasis and type 2 diabetes mellitus (odds ratio [OR], 1.53; 95\% CI, 1.03 $2.27 ; \mathrm{P}=.04)[22]$.

In our study as inferred from tables $1 \& 6$, metabolic syndrome was not associated with psoriasis disease and severity and consistent with our study, Nisa and Qazi reported that PASI $>10$ was more common in patients without metabolic syndrome $(\mathrm{P}>0.050)$ and also Shankar U, et al. and Lakshmi S, et al. did not show any association of diabetes with psoriasis [23,24].

\section{Association with hypertension}

As shown in Table 2 prevalence of hypertension in cases of psoriasis was $13.33 \%$ as compared to in $15.33 \%$ controls which was consistent with that of an Indian study by Alexander, et al. which revealed a prevalence of hypertension in only $8.1 \%$ of psoriasis patients. This however was in contrast to a study done by Alexander E, et al. Pinto J, et al. Pal GS, et al. [16].

Cohen, et al. in their study reported that the prevalence of hypertension was significantly higher in psoriasis patients than controls (38.8\%, 29.1\% respectively). Similar results were noted by Sommer, et al $[19,20]$. Thus, there was no significant increase in prevalence of hypertension in patients with psoriasis (p value: 0.741 ).

\section{Association with lipid parameters}

According to table $4.50 .67 \%$ of the cases had serum triglycerides within the normal range as compared to $59.3 \%$ of the controls and according to table 6 the mean value in cases was 179.81 which was nearly equal to the mean value in controls which was 176 . ( $\mathrm{p}$ val$\mathrm{ue}=0.732$ ).

Table 4 shows. $66.67 \%$ of the cases had serum HDL within the normal range as compared to 62 of the controls. Thus, no significant difference in HDL values was seen in cases and controls ( $p$ value 0.399 ). Similarly, Madanagobalane S, et al. and Anandan S, et al. did not find any significant association of raised HDL and hypertension with psoriasis [17].

Also, Toker M, et al. Kadi A, et al. Yildirim K, et al. Aksoy H, and Akçay F, et al. did not find any correlation of derranged lipid profile with psoriasis [25].

Nakhwa YC, Rashmi R, Bhasavraj KS, et al. in their study in 2014, found no association between lipid profile and psoriasis [26].

In a chinese study no association was found between Serum levels of triglyceride and LDL and psoriasis [27].

Even in a recent study done by Kothiwala SK, Khanna N, Tandon $\mathrm{N}$, et al. no correlation was seen between $\mathrm{Sr} \mathrm{HDL}$ and $\mathrm{Sr} \mathrm{TG}$ and psoriasis [28].

There was a uniformly higher prevalence of all components of metabolic syndrome in men and women with psoriasis compared with those without across all age groups in a study done by Danielsen K, Wilsgaard T, Olsen AO, Eggen AE, Olsen K, Cassano PA, Furberg AS et al. [29]

In our study as evident from table 3, prevalence of obesity among cases was $17.33 \%$ and $13.33 \%$ among controls so, there was no association between obesity and psoriasis ( $p$ value $=0.153$ ). 
In contrast Madanagobalane and Anandan, reported a higher prevalence of obesity in psoriasis patients than in controls [17]

\section{Summary}

- While comparing 150 age and sex matched cases and controls, $17.33 \%$ cases as compared to $14 \%$ controls had hyperglycemia which may be due to most common age group affected being 41-50 years, which is also common age group for onset of diabetes

- In our study $13.33 \%$ cases and $15.33 \%$ controls were hypertensives

- This slightly higher prevalence in general population may be due to stress of regular accompaniment of their patients during recurrent opd visits or long absence from work

- $44.67 \%$ while $42.67 \%$ controls had serum TG $>150 \mathrm{mg} / \mathrm{dl}$

- $33.33 \%$ of patients while $38 \%$ of controls had $\mathrm{HDL}<40 \mathrm{mg} / \mathrm{dl}$

So, it can be concluded that there was no association of psoriasis with lipid parameters.

It may be due to the fact that most of rural population of India especially Bihar are not capable enough of consuming fat rich meals, do a lot of manual work and involved in many rigorous activities.

Our study, clearly refuted any association of psoriasis with metabolic syndrome in Indian patients. The plenty of reports from west approving such an association can be explained on the basis of increased prevalence of obesity, abnormal BMI and hypertension in westerners as compared to Indian patients. In addition, there is also higher prevalence of coexistent risk factors like smoking and alcohol intake in the west which may contribute to the morbidity and prevalence of metabolic syndrome. Further most such studies have been conducted on patients on treatment while our study has been done on newly diagnosed patients prior to the initiation of any therapy.

Looking at various studies around the world, which included population samples, aged from 20 to 25 and upwards, the prevalence of metabolic syndrome in healthy adults varies from $8 \%$ in India to $24 \%$ in United States in men. This goes on to prove that there are additional metabolic and risk factors that contribute to the increased prevalence of metabolic syndrome in western patients.

This has important implications for treating dermatologist as it allows them to be more adventurous and aggressive in treating these patients while simultaneously saving the cost of expensive unnecessary investigations that they may resort to rule out underlying metabolic syndrome.

\section{References}

1. Langley RG, Krueger GG, Griffiths CE (2005) Psoriasis: Epidemiology, clinical features, and quality of life. Ann Rheum Dis 64: 18-23.

2. Brandrup F, Green A (1981) The prevalence of psoriasis in Denmark. Acta Derm Venereol 61: 344-346.

3. Davidovici BB, Sattar N, Prinz J, Puig L, Emery P, et al. (2010) Psoriasis and systemic inflammatory diseases: Potential mechanistic links between skin disease and co-morbid conditions. J Invest Dermatol 130: 1785-1796.

4. Ghiasi M, Nouri M, Abbasi A, Hatami P, Abbasi MA, et al. (2011) Psoriasis and increased prevalence of hypertension and diabetes mellitus. Indian J Dermatol 56: 533-536.
5. Okhandiar RP, Banerjee BN (1963) Psoriasis in the tropics: An epidemiological survey. J Indian Med Assoc 41: 550-556.

6. Bedi TR (1995) Clinical profile of psoriasis in North India. Indian J Dermatol Venereol Leprol 61: 202-205.

7. Henseler T, Christophers E (1995) Disease concomitance in psoriasis. J Am Acad Dermatol 32: 982-986.

8. Myers WA, Gottlieb AB, Mease P (2006) Psoriasis and psoriatic arthritis: Clinical features and disease mechanisms. Clin Dermatol 24: 438-447.

9. Gottlieb AB, Chao C, Dann F (2008) Psoriasis comorbidities. J Dermato$\log$ Treat 19: 5-21.

10. Zhao YF, Feng DD, Chen C (2006) Contribution of adipocyte-derived factors to beta-cell dysfunction in diabetes. Int $\mathrm{J}$ Biochem Cell Biol 38: 804-819.

11. Gisondi P, Tessari G, Conti A, Piaserico S, Schianchi S, et al. (2007) Prevalence of metabolic syndrome in patients with psoriasis: A hospital-based case-control study. Br J Dermatol 157: 68-73.

12. Azfar RS, Gelfand JM (2008) Psoriasis and metabolic disease: Epidemiology and pathophysiology. Curr Opin Rheumatol 20: 416-422.

13. Wang Y, Chen J, Zhao Y, Geng L, Song F, et al. (2008) Psoriasis is associated with increased levels of serum leptin. Br J Dermatol 158: 1134-1135.

14. Boehncke S, Thaci D, Beschmann H, Ludwig RJ, Ackermann H, et al. (2007) Psoriasis patients show signs of insulin resistance. Br J Dermatol 157: $1249-1251$.

15. Sundharam JA, Singh R, Agarwal PS (1980) Psoriasis and Diabetes Millitus. Indian J Dermatol Venereol Leprol 46: 158-162.

16. Alexander E, Pinto J, Pal GS, Kamath N, Kuruvilla M (2001) Disease concomitance in psoriasis: A clinical study of 61 cases. Indian J Dermatol Venereol Leprol 67: 66-68.

17. Madanagobalane M, Anandan S (2012) Prevalence of Metabolic Syndrome in South Indian Patients with Psoriasis Vulgaris and the Relation between Disease Severity and Metabolic Syndrome: A Hospital-Based Case-Control Study. Indian J Dermatol 57: 333-357.

18. Neimann AL, Shin DB, Wang X, Margolis DJ, Troxel AB, et al. (2006) Prevalence of cardiovascular risk factors in patients with psoriasis. J Am Acad Dermatol 55: 829-835.

19. Sommer DM, Jenisch S, Suchan M, Christophers E, Weichenthal M (2006) Increased prevalence of the metabolic syndrome in patients with moderate to severe psoriasis. Arch Dermatol Res 298: 321-328.

20. Shapiro J, Cohen AD, David M, Hodak E, Chodik G, et al. (2007) The association between psoriasis, diabetes mellitus, and atherosclerosis in Israel: a case-control study. J Am Acad Dermatol 56: 629-634.

21. Ali NM, Kuruvila M, Unnikrishnan B (2014) Psoriasis and metabolic syndrome: A case control study. IJDVL 80: 255-257.

22. Lønnberg AS, Skov L, Skytthe A, Kyvik KO, Pedersen OB, et al. (2016) Association of Psoriasis With the Risk for Type 2 Diabetes Mellitus and Obesity, JAMA Dermatol 152: 761-767.

23. Nisa N, Qazi MA (2010) Prevalence of metabolic syndrome in patients with psoriasis. Indian J Dermatol Venereol Leprol 76: 662-665.

24. Lakshmi S, Nath AK, Udayashankar C (2014) Metabolic syndrome in patients with psoriasis: A comparative study. Indian Dermatol Online J 5: 132-137.

25. Toker A, Kadi M, Yildirim AK, Aksoy H, Akçay F (2009) Serum lipid profile paraoxonase and arylesterase activities in psoriasis. Cell Biochem Funct 3: 176-180. 
26. Nakhwa YC, Rashmi R, Basavaraj KH (2014) Dyslipidemia in Psoriasis: A Case Controlled Study. International Scholarly Research Notices 729157: 5.

27. Pang X, Lin K, Liu W, Zhang P, Zhu S (2015) Characterization of the abnormal lipid profile in Chinese patients with psoriasis. Int J Clin Exp Pathol 8: 15280-15284.

28. Kothiwala SK, Khanna N, Tandon N, Naik N, Sharma VK, et al. (2016) Prevalence of metabolic syndrome and cardiovascular changes in patients with chronic plaque psoriasis and their correlation with disease severity: A hospital-based cross-sectional study. Indian J Dermatol Venereol Leprol 82: $510-518$.
29. Danielsen K, Wilsgaard T, Olsen AO, Eggen AE, Olsen K, et al. (2015) Elevated odds of metabolic syndrome in psoriasis: a population-based study of age and sex differences 172: 419-427. 


\section{di \\ нетан}

Advances In Industrial Biotechnology | ISSN: 2639-5665

Advances In Microbiology Research | ISSN: 2689-694X

Archives Of Surgery And Surgical Education | ISSN: 2689-3126

Archives Of Urology

Archives Of Zoological Studies | ISSN: 2640-7779

Current Trends Medical And Biological Engineering

International Journal Of Case Reports And Therapeutic Studies | ISSN: 2689-310X

Journal Of Addiction \& Addictive Disorders | ISSN: 2578-7276

Journal Of Agronomy \& Agricultural Science | ISSN: 2689-8292

Journal Of AIDS Clinical Research \& STDs | ISSN: 2572-7370

Journal Of Alcoholism Drug Abuse \& Substance Dependence | ISSN: 2572-9594

Journal Of Allergy Disorders \& Therapy | ISSN: 2470-749X

Journal Of Alternative Complementary \& Integrative Medicine | ISSN: 2470-7562

Journal Of Alzheimers \& Neurodegenerative Diseases | ISSN: 2572-9608

Journal Of Anesthesia \& Clinical Care | ISSN: 2378-8879

Journal Of Angiology \& Vascular Surgery | ISSN: 2572-7397

Journal Of Animal Research \& Veterinary Science | ISSN: 2639-3751

Journal Of Aquaculture \& Fisheries | ISSN: 2576-5523

Journal Of Atmospheric \& Earth Sciences | ISSN: 2689-8780

Journal Of Biotech Research \& Biochemistry

Journal Of Brain \& Neuroscience Research

Journal Of Cancer Biology \& Treatment | ISSN: 2470-7546

Journal Of Cardiology Study \& Research | ISSN: 2640-768X

Journal Of Cell Biology \& Cell Metabolism | ISSN: 2381-1943

Journal Of Clinical Dermatology \& Therapy | ISSN: 2378-8771

Journal Of Clinical Immunology \& Immunotherapy | ISSN: 2378-8844

Journal Of Clinical Studies \& Medical Case Reports | ISSN: 2378-8801

Journal Of Community Medicine \& Public Health Care | ISSN: 2381-1978

Journal Of Cytology \& Tissue Biology | ISSN: 2378-9107

Journal Of Dairy Research \& Technology | ISSN: 2688-9315

Journal Of Dentistry Oral Health \& Cosmesis | ISSN: 2473-6783

Journal Of Diabetes \& Metabolic Disorders | ISSN: 2381-201X

Journal Of Emergency Medicine Trauma \& Surgical Care | ISSN: 2378-8798

Journal Of Environmental Science Current Research | ISSN: 2643-5020

Journal Of Food Science \& Nutrition | ISSN: 2470-1076

Journal Of Forensic Legal \& Investigative Sciences | ISSN: 2473-733X

Journal Of Gastroenterology \& Hepatology Research | ISSN: 2574-2566
Journal Of Genetics \& Genomic Sciences | ISSN: 2574-2485

Journal Of Gerontology \& Geriatric Medicine | ISSN: 2381-8662

Journal Of Hematology Blood Transfusion \& Disorders | ISSN: 2572-2999

Journal Of Hospice \& Palliative Medical Care

Journal Of Human Endocrinology | ISSN: 2572-9640

Journal Of Infectious \& Non Infectious Diseases | ISSN: 2381-8654

Journal Of Internal Medicine \& Primary Healthcare | ISSN: 2574-2493

Journal Of Light \& Laser Current Trends

Journal Of Medicine Study \& Research | ISSN: 2639-5657

Journal Of Modern Chemical Sciences

Journal Of Nanotechnology Nanomedicine \& Nanobiotechnology | ISSN: 2381-2044

Journal Of Neonatology \& Clinical Pediatrics | ISSN: 2378-878X

Journal Of Nephrology \& Renal Therapy | ISSN: 2473-7313

Journal Of Non Invasive Vascular Investigation | ISSN: 2572-7400

Journal Of Nuclear Medicine Radiology \& Radiation Therapy | ISSN: 2572-7419

Journal Of Obesity \& Weight Loss | ISSN: 2473-7372

Journal Of Ophthalmology \& Clinical Research | ISSN: 2378-8887

Journal Of Orthopedic Research \& Physiotherapy | ISSN: 2381-2052

Journal Of Otolaryngology Head \& Neck Surgery | ISSN: 2573-010X

Journal Of Pathology Clinical \& Medical Research

Journal Of Pharmacology Pharmaceutics \& Pharmacovigilance | ISSN: 2639-5649

Journal Of Physical Medicine Rehabilitation \& Disabilities | ISSN: 2381-8670

Journal Of Plant Science Current Research | ISSN: 2639-3743

Journal Of Practical \& Professional Nursing | ISSN: 2639-5681

Journal Of Protein Research \& Bioinformatics

Journal Of Psychiatry Depression \& Anxiety | ISSN: 2573-0150

Journal Of Pulmonary Medicine \& Respiratory Research | ISSN: 2573-0177

Journal Of Reproductive Medicine Gynaecology \& Obstetrics | ISSN: 2574-2574

Journal Of Stem Cells Research Development \& Therapy | ISSN: 2381-2060

Journal Of Surgery Current Trends \& Innovations | ISSN: 2578-7284

Journal Of Toxicology Current Research | ISSN: 2639-3735

Journal Of Translational Science And Research

Journal Of Vaccines Research \& Vaccination | ISSN: 2573-0193

Journal Of Virology \& Antivirals

Sports Medicine And Injury Care Journal | ISSN: 2689-8829

Trends In Anatomy \& Physiology | ISSN: 2640-7752

Submit Your Manuscript: https://www.heraldopenaccess.us/submit-manuscript 